\title{
INSIGHTS
}

\section{Family reflections: Prematurity-practitioner influence on the lived experience of the parenting role}

\author{
Sue Sharpe ${ }^{1}$ \\ Pediatric Research (2019) 86:283-284; https://doi.org/10.1038/s41390-019-0351-6
}

As a parent of two premature infants with very different outcomes, I've experienced the NICU in its many forms. My daughter, born at $23 \mathrm{w} 4 \mathrm{~d}$, lived 3 weeks before dying from necrotising enterocolitis (NEC); my son, born at $25 \mathrm{w}$ 0d, survived and was discharged after 113 days as an inpatient. Between our two children, our family has weathered each type of respiratory support (ventilation, high frequency ventilation, CPAP, high flow and low flow), feeding support (intravenous nutrition, orogastric tube, nasogastric tube, bottle and breast) and a broad range of other comorbidities and complications, including a patent ductus arteriosus (PDA), subsequent pulmonary haemorrhage, mild intraventricular bleed and retinopathy of prematurity (ROP), each requiring treatment.

I could speak to the areas of research needing greater funding and attention, but in truth this would be biased by the diagnoses given to my own children. In my lived experience, our children would have benefitted from a more effective method to treat (or prevent) NEC infection in peri-viable infants, or criteria to predict which babies' PDA will cause life-threatening complications. In a broader view, long term studies and follow up are desperately needed to truly add the 'informed' to informed consent for parents.

Examples include our daughter's treatment for lung disease and her later NEC diagnosis. The informed consent process for steroid treatment included information about increased later risk of cerebral palsy and other disabilities, but other than the immediacy of treatment after her birth and the dosage and duration of her treatment, there was little else to assist us to predict whether she would be one of those affected, or how much of an increased risk existed in this instance.

In regards to her NEC diagnosis, we were given a list of the issues that increased her risks: moving her to another hospital; transport that doesn't allow for high frequency ventilation; sedation; surgery itself (exploratory first, as the affected area wasn't visible on imaging), the stress of recovery. Our decisions in each instance were different, but both were very much based on longer term outcomes. Yes, we were willing to take the increased risk of disability in the instance of steroid treatment. No, we were not willing to take substantial risk in NEC surgery of disability and or death without our presence. We chose to gently withdraw treatment. In the absence of a crystal ball, long term studies are vital to the choices we make and allow ourselves to live with the consequences, as well as ensure we're equipped to care for the child if they arrive home.

I also encourage practitioners and researchers to consider your unique capacity to give or take away from family quality of life while you act to extend the quantity of life of the children.
Premature birth takes many things from parents, impacting on experiences of pregnancy and birth, bonding and breastfeeding, parenting, participation and celebration. Despite carrying two children, l've never experienced the third trimester in all its discomfort, never had a baby shower, never made a happy birth announcement, nor had the immediate skin to skin contact or breastfeeding that I had planned. Plans and control are removed and were replaced by daily apprehension. 'What will today bring?' 'What will happen next?' Unlike most parents, I couldn't offer what I felt were the most basic of protections to my children during their gestation and, issues of guilt aside, this changes parental thinking.

While a hospital may have developed procedures to ensure that parents can participate in nappy changes or feeds, parenting (inside the hospital and out) isn't simply participating in that child's 'cares'; it extends to decision-making for that child. Full of good intentions and fervour, parents of full term babies may direct their intensity towards hundreds of small decisions in daily life: capsule or car seat, whether to use paracetamol prior to an immunisation, to change nappy brand, how much tummy time to provide, etc. Deprived of this day-to-day empowerment, NICU parenting takes a distinctly different flavour.

'Premmie parents' may deeply interrogate medical decisions or other care decisions. The hospital mothers' group reflected to me that I wasn't alone in this, and that the drive to retain control appeared almost universal. Once determining what we believe is best for our child, driven at all costs to protect them, we can develop an apparent fixation on the issue. In the casual conversation of this weekly group I witnessed countless examples of parents requesting to personalise care, often single-minded in its pursuit regardless of authorisation from the hospital. One mother became passionately focused on moving her baby to an open cot as soon as possible; another insisted on personally giving the handover at rounds; a third chose to bottle-feed her baby expressed breastmilk rather than breastfeed, expending countless hours to ensure she could precisely measure the intake of her baby. For myself, I was driven to ensure that my son was able to taste breastmilk as soon as possible despite not yet being able to feed.

Restricting decision-making in areas of parent-perceived importance can have larger impacts on the child, the parents and potentially the hospital or beyond. At best, there's subsequent resistance or clandestine behaviour that sets an oppositional dynamic with the care team. One woman gleefully relayed 'smuggling' in her own choice of non-approved moisturiser. More concerningly, when a parent who had wished for a specific nonmedical intervention for her child was informed that this strictly

${ }^{1}$ Melbourne, Australia
Correspondence: Sue Sharpe (info@pedres.org)

Received: 15 February 2019 Accepted: 15 February 2019

Published online: 21 February 2019 
could not be provided outside of an ongoing study, the infant was enroled as a participant-only to be randomised into the non-intervention group. The parents then covertly applied the intervention regardless, frustrated at the inability to discuss provision outside the research sphere. At worst, denial of parent choice might contribute to a sense of helplessness and remove an empowering coping strategy.

While parent decisions may not always be able to be accommodated, they should always be respected and considered carefully: premmie parents can't simply discharge their child or move them to another hospital, and they can't enact their parenting in other spheres. I urge you to interrogate your own reasoning behind denying any parent choice for their child, as this decision may come at the cost of their perceived parenting selfefficacy or anxiety regarding the infant's health and wellbeing.

Sometimes there is a mismatch between the perceived magnitude of the medical condition between parent and practitioner. For our son, his retinopathy of prematurity (ROP) diagnosis and treatment came relatively late in a hospital stay where our thoughts had turned from survival to future function. It would be easy to presume the issue of eyesight was less significant than previous life-threatening diagnoses and interventions. His death however was no longer 'on the table' in our minds, and so the scales of severity had already shifted. This condition and the possibility of laser treatment threatened the life that we had imagined for him. ROP was explained to us using concepts such as zones and plus disease, and eventually led to discussion about field of vision limitations, but all that we wanted was to know the later life implications. Would our son ever drive? Would he ride a bike or play sport? Could he balance effectively and walk and crawl in the usual time frame? This was something that wasn't able to be accurately predicted and caused us great concern for our son's future.
ROP diagnosis came at the end of a long line of health concerns. The eye checks were distressing to watch, but often it was far more distressing to leave the room, hear our son screaming and consider the failure of parenting we represented when we forced our child to experience something that we couldn't even witness. Inaccurate though this assessment may be, ROP was the 'one more thing' at a point where our fatigue with the prematurity pathway was high. The emotional impact was therefore greater than it otherwise might have been, if we had not faced countless other discussions, both in the realm of medical mountains and molehills. In this way, I would ask practitioners to be aware that, while they speak to a parent of a relatively healthy surviving child that they consider they're actually speaking to exhausted, barely surviving parents at the end of an exhausting journey. The patience for each might be proportionately different, and require tolerance for jumping to the worst case scenario and potentially fixating on it. That said, our ophthalmologist and supporting nurses were all of those things, as well as gently unflappable in the face of my insistence on staying in the room and crying as I watched the eye check procedure each time.

NICU wards now commonly adopt a family-centred approach recognising the importance of the parents to the infant's survival and health. It's my experience that parents often feel disempowered nonetheless, as their expected role extends much further than physical contact and basic care needs. Further research should be carried out in regards to this disparity between the expected and actual role, and its influence on later parenting capacity and engagement, mental health and the subsequent impact on cognitive outcomes for the child. In the meantime, I urge that all members of the health team consider allowing parental control over in instances where there is no compelling evidence that health or financial outcomes will be impacted. This is a more truly family-centred approach. 